\title{
13 PALLIATIVE CARE: AN ALTERNATIVE TO EUTHANASIA
}

B A Omipidam ${ }^{1}{ }^{1}$ Faculty of Law, University of Ilorin, Ilorin, P.M.B55, Ilorin, Kwara State, Nigeria

\subsection{6/bmjspcare-2013-000491.13}

Background Today, euthanasia has become the option for terminally ill persons, in order to die with dignity. Palliative care on the other hand seeks to re-assure people with terminal or chronic ailments that they are still worthy of living.

Aim To show case Palliative care as an efficient alternative to euthanasia for terminally ill persons.

Methods I examined request for euthanasia and or assisted suicide on the basis of personal interviews carried out on terminally ill patients in the six geopolitical zones of Nigeria in the last 24 months; current arguments for and against the concept and views expressed by stake-holders on the concept.

Results Outcome of the study carried out shows that request for euthanasia and or assisted suicide, are largely due to the fear of being a burden and abandoned by families and relatives.

Discussion Since it deals with care rather than cure, a combination of doctors, nurses and social work palliative care specialists, Massage therapists, pharmacists, nutritionists, chaplains, amongst others, will re-assure terminally and chronically ill patients that they are not a burden, and that the remaining part of their lives are worth living.

Conclusion Palliative care should be the focus of all government across the globe so that, terminally and chronically ill persons can be adequately catered for as they approach their end of life. If this is wholly embraced, the request for euthanasia and or assisted suicide will be condemned to the dustbin of history. 